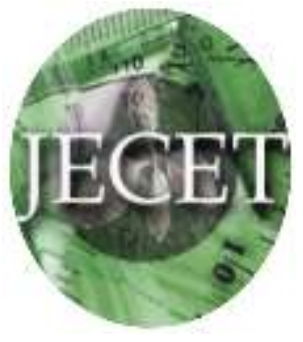

Research Article

Jaurnal of Enviranmental Science, Camputer Science and Engineering \& Technology

An International Peer Review E-3 Journal of Sciences and Technology

Available online at www.jecet.org

Section A: Environmental Science

\title{
Fluoride Contamination of Underground Water during Winter Season in Dindigul District, Tamilnadu
}

\author{
Prem Anand $\mathbf{J}^{1}$, Ananthanarayanan $\mathrm{L}^{\mathbf{2}}$ and Somasundaram $\mathbf{N}^{1,3^{*}}$ \\ ${ }^{1}$ Department of Environmental Engineering, PRIST University, Thanjavur at Madurai Campus, \\ Madurai, India \\ ${ }^{2}$ Department of Chemistry, PAC Ramasamy Raja Polytechnic College, Rajapalayam, India \\ ${ }^{3}$ Department of Chemistry, Rukmini Shanmugam Polytechnic College, Varichiyur, Madurai, India
}

Received: 18 July 2018; Revised: 03 August 2018; Accepted: 12 August 2018

\begin{abstract}
Fluoride is consumed by humans predominantly through drinking water. Eventhough, many reports published in the fluoride area, it is necessary to measure fluoride content time to time in the high risk parts of the country like Dindigul and Dharmapuri districts of Tamilnadu state to adopt remedial measures and creating awareness to the people living in the area. Due to population explosion in the prone places of employment opportunities and outskirts of the cities, particularly the high risk factor of reported fluoride endemic parts should be monitored periodically to understand environmental impact and the changes in physical parameters, chemical and geological aspects. In southern part of India, Dindigul district is found to be one of the high fluorosis affected places. Certain parts of the district were chosen randomly after going through the literature thoroughly as study area in particularly, the winter season. Many changes in the concentration level of fluoride have been expected due to rain water seepage, runoff from agricultural field, dilution of surface water, etc.
\end{abstract}

Keywords: Fluoride, underground water, fluorosis, drinking water 


\section{INTRODUCTION}

Authorities of regular municipal water supply have not been giving much attention to check the level of fluoride by testing. This may be due to lack of awareness, laboratory setup and all. Dindigul district of Tamilnadu state is found to be one among the high fluorosis affected parts of the country. This study brings the information about the fluoride level of 75-100 samples collected from 15 villages of the district during winter season. The risk factor was classified into three categories as reported elsewhere.

Vadamadurai block of Dindigul district was found to be affected by dental fluorosis in dangerous level. Certain isopleths map reports already established were used as reference for identification of exact geographical location of high fluoride exposed area is much useful to perform remedial measures and is helpful to give awareness about fluorosis to the villagers residing in the particular area.

A total of 15 villages belonging to Dindigul, Vadamadurai, Shanarpatti blocks of Dindigul district of Tamil Nadu were chosen in this study randomly. 10 samples of drinking water were collected from different parts of each and every village by almost covering most area during late winter season. Similarly 75 to 100 samples were collected and analyzed for fluoride level. Collected samples were kept in precleaned, polyethylene bottles and stored in a refrigerator till being analyzed. Using fluoride ion selective electrode Orion 9609, fluoride was measured. Cyclohexylene dinitrilo tetra acetic acid buffer was added to the standard water and to the collected samples. The instrument was calibrated with standard solutions of different fluoride concentrations and the concentrations of the unknown samples were directly read from the meter.

\section{METERIALS AND METHODS}

In three blocks of the district, villages were classified into three categories such as normal area, medium fluoride endemic area and high fluoride endemic area at which the fluoride level in the drinking water $<1$ $\mathrm{mg} / \mathrm{l}, 1-2 \mathrm{mg} / \mathrm{L}$ and $>2 \mathrm{mg} / \mathrm{L}$. Clinical survey was conducted by getting help from local self-help groups among the people of those villages including school children of age group in between 5 to 70 . The percentage fluorosis was calculated from the number of people affected from the villages listed in Table 1 by fluorosis with total number of humans surveyed. Nearly, 1000 school children aged between 5 to 15 and 800 adults within the age group were randomly selected and examined for this study. This clinical survey was done in 15 villages and 15 schools. The clinical identification and characterization of dental fluorosis were confirmed by the help of Dentists.

The fluoride exposure dose was calculated by the following relation:

\section{Fluoride exposure dose $=(\mathrm{F} \times \mathrm{V}) / \mathrm{M}$}

Where, F, the concentration fluoride in ppm, $\mathbf{V}$, the volume of water intake in L/day and $\mathbf{M}$, the body weight in $\mathrm{kg}$. The water intake level of infants, children and adults were accounted through random household investigation. Approximately, infants fed $250 \mathrm{~mL}$ of boiled water every day. When water is boiling, fluoride concentration increases proportionally to the loss of volume, so the level of fluoride in tap water is doubled. The estimated water intake for children and adult was 1.0 and $3.0 \mathrm{~L} / \mathrm{day}$, 
respectively. For the calculation, body weight of infants in the age group of 0-6 months was kept as $6 \mathrm{~kg}$ and of children aged between 7 years to adulthood as $20 \mathrm{~kg}$ and that of adults above 20 years as $70 \mathrm{~kg}$. The mean of minimum and maximum range of water fluoride level in each block was used for minimum and maximum exposure dose calculation.

Analysis report showed from the collected 50 samples in 5 villages of Vadamadurai block are $20 \%$ of the samples recorded fluoride level between 1.0 and $3 \mathrm{ppm}$ whereas in $80 \%$ of the samples, fluoride concentration was well within the limit that is less than $0.5 \mathrm{ppm}$. The average fluoride level was found to be $1.08 \mathrm{ppm}$. This observation is comparable in the study report of water fluoride in villages of Krishnagiri district of Tamil Nadu from documented reports. The calculated exposure dose level of fluoride for infants was between 0.05 and $0.12 \mathrm{ppm} / \mathrm{day}$, for children it was between 0.05 and 0.10 $\mathrm{ppm} /$ day and adults had 0.03 to $0.07 \mathrm{ppm} /$ day of exposure dose level.

Drinking water samples from Vadamadurai block are also contaminated with excess fluoride.Nearly20\% of the samples collected had fluoride concentrations between 1.0 and $3 \mathrm{ppm}$. Due to the high fluoride level of drinking water, and this block is also considered as fluoride endemic area. Infants in this block are consuming ten-fold higher fluoride concentrations than the safer threshold level. The exposure of fluoride dosage for children and adults is also little higher, so the humans of this block are also facing the problem of fluorosis.

\section{RESULTS AND DISCUSSION}

In the study areas of Dindigul district, the rate of fluorosis increases with increase of fluoride level in drinking water and age. Being ground water is the main drinking water source of these selected study areas, abnormal concentrations of fluoride is commonly observed in fractured hard rock zone with pegmatite veins. The ground water may contribute to high fluoride levels in the drinking water sources due to leaching of fluoride ions. The present findings indicate that the children (5-14 years) and adults (25-70 years) are equally affected by dental fluorosis. Male gender both adult and children are affected by high fluorosis than females. Previous reports also showed that boys and male adults are prone to fluorosis. Perhaps, there was no report proved that fluorosis is sex dependent but nutritional habits, especially breast feeding, climatic conditions, play a major role in the prevalence of fluorosis. The weather condition of the study area is warmest than the nearby areas wherein the people consume more drinking water: this may be another reason to the susceptible fluorosis.

Moreover, male gender consumes more water than females, which enhances the daily fluoride intake level among boys and men in the study area. Children residing in fluoride endemic areas are exposed to more fluoride. Previous reports showed a significant inverse relationship between the fluoride concentration and the intelligence quotient (IQ) of children. Fluoride level in drinking water increases with the IQ decrease and mental retardation rates as well as borderline intelligence increase. Consumption of more fluoride intake through drinking water in children may cause adverse affects to the mid-brain and neurotransmitters. The current investigation reveals that few villages are the high fluoride endemic parts. The drinking water fluoride levels in these villages are as high as $4.0 \mathrm{ppm}$. 
Table 1: Drinking water fluoride concentrations (ppm) in villages of Dindigul block of Dindigul District, Tamil Nadu, India

\begin{tabular}{|l|l|l|l|l|l|l|}
\hline Village & Sample 1 & Sample 2 & Sample 3 & Sample 4 & Sample 5 & Mean \\
\hline Dindigul & 0.61 & 0.59 & 0.48 & 0.68 & 0.58 & 0.59 \\
\hline Saveriyarpalayam & 0.48 & 0.49 & 0.47 & 0.47 & 0.48 & 0.48 \\
\hline A.Vellodu & 0.56 & 0.64 & 0.58 & 0.51 & 0.57 & 0.57 \\
\hline Kovilur & 0.64 & 0.59 & 0.69 & 0.61 & 0.67 & 0.64 \\
\hline Settinayakanpatti & 0.49 & 0.48 & 0.51 & 0.47 & 0.49 & 0.49 \\
\hline
\end{tabular}

Table 2: Drinking water fluoride concentrations ( $\mathrm{ppm}$ ) in villages of Vadamadurai block of Dindigul District, Tamil Nadu, India

\begin{tabular}{|l|c|c|c|c|c|c|}
\hline Village & Sample 1 & Sample 2 & Sample 3 & Sample 4 & Sample 5 & Mean \\
\hline Vadamadurai & 1.52 & 1.24 & 1.44 & 0.98 & 1.17 & 1.27 \\
\hline Sukkampatti & 1.20 & 1.23 & 1.36 & 0.89 & 0.98 & 1.13 \\
\hline Ramanathapuram & 1.31 & 1.26 & 1.19 & 1.35 & 1.22 & 1.27 \\
\hline Ayyalur & 1.13 & 1.23 & 1.07 & 0.98 & 0.97 & 1.08 \\
\hline Kulathur & 0.74 & 0.44 & 0.48 & 0.67 & 0.58 & 0.58 \\
\hline
\end{tabular}

Table3: Drinking water fluoride concentrations (ppm) in villages of Shanarpatti block of Dindigul District, Tamil Nadu, India

\begin{tabular}{|l|c|c|c|c|c|c|}
\hline Village & Sample 1 & Sample 2 & Sample 3 & Sample 4 & Sample 5 & Mean \\
\hline Shanarpatti & 0.96 & 1.08 & 0.71 & 0.79 & 0.87 & 0.90 \\
\hline Konapatti & 0.56 & 0.85 & 0.67 & 0.51 & 0.69 & 0.68 \\
\hline Viralipatti & 0.66 & 0.65 & 0.74 & 0.86 & 0.80 & 0.74 \\
\hline Maranuthu & 0.73 & 0.63 & 0.57 & 0.54 & 0.64 & 0.62 \\
\hline Siluvathur & 0.66 & 0.67 & 0.57 & 0.55 & 0.68 & 0.63 \\
\hline
\end{tabular}


Table 4: Level of fluorosis among school children in Dindigul district.

\begin{tabular}{|c|c|c|}
\hline Area category & $\begin{array}{c}\text { No. of Students } \\
\text { surveyed }\end{array}$ & $\begin{array}{c}\text { No. of Students } \\
\text { affected }\end{array}$ \\
\hline Normal area $(\mathrm{N})$ & 1300 & 358 \\
\hline Medium fluoride endemic area $(\mathrm{M})$ & 200 & 72 \\
\hline High fluoride endemic area $(\mathrm{H})$ & 100 & 25 \\
\hline
\end{tabular}

Table 5: Level of fluorosis among humans in Dindigul district.

\begin{tabular}{|c|c|c|}
\hline Area category & $\begin{array}{c}\text { No. of Students } \\
\text { surveyed }\end{array}$ & $\begin{array}{c}\text { No. of Students } \\
\text { affected }\end{array}$ \\
\hline Normal area (N) & 1300 & 272 \\
\hline $\begin{array}{c}\text { Medium fluoride endemic } \\
\text { area (F1) }\end{array}$ & 200 & 54 \\
\hline $\begin{array}{c}\text { High fluoride endemic area } \\
\text { (F2) }\end{array}$ & 100 & 59 \\
\hline
\end{tabular}

Table 6: Fluoride exposure dose through drinking water for various age groups of people of Dindigul District.

\begin{tabular}{|l|c|c|c|c|c|c|}
\hline \multirow{2}{*}{ Area Category } & \multicolumn{5}{|c|}{ Fluoride exposure dose level ppm//day) } \\
\cline { 2 - 7 } & \multicolumn{2}{|c|}{ Infants } & \multicolumn{2}{c|}{ Children } & \multicolumn{2}{c|}{ Adults } \\
\cline { 2 - 7 } & Minimum & Maximum & Minimum & Maximum & Minimum & Maximum \\
\hline N & 0.007 & 0.070 & 0.007 & 0.070 & 0.003 & 0.040 \\
\hline F1 & 0.020 & 0.160 & 0.020 & 0.140 & 0.010 & 0.050 \\
\hline F2 & 0.030 & 0.300 & 0.025 & 0.280 & 0.015 & 0.150 \\
\hline
\end{tabular}

N = Normal, F1 = Medium fluoride endemic area, F2 = High fluoride endemic area.

Finding out exact location of fluoride endemic parts through mapping are highly useful to government agencies for supplying water with admissible fluoride concentration, establishing defluoridation plants and for conducting various awareness creation programmes. Infants in Vadamadurai block of Dindigul district are found to be highly exposed to fluoride level than children and adults. Particularly, infants in high fluoride endemic parts are exposed to fluoride through drinking water by nearly 25 times more (Table 5) than the admissible level of $0.01 \mathrm{ppm} /$ day. Drinking water is an important route for fluoride exposure, since the presence of bio-available soluble fluorides. Apart from drinking water, infants commonly consume milk and powder-based milk formulae; Milk is known to interfere with the rate of fluoride absorption. Milk and milk products diminish the fluoride availability through gastrointestinal tract by $25-50 \%$ in humans, due to the presence of high calcium concentrations. Milk is also containing rich fats, may increase the lag time of the food in the body (stomach). 
Also, the rate of fluorosis among children below 2 years is lower than that of other children of other age groups. The humans in normal areas consume less fluoride through drinking water. Bu they are affected by dental fluorosis symptoms mainly because of using tea, coffee and tooth paste. The fluoride exposure dose level decreases with increase from children to adults. The results of the present findings are highly comparable with the previous report. In these areas, people consume sorghum and pearl millet as the chief staple foods regularly. The intake of diets based on sorghum and pearl millet resulted in significant increase in retention of fluoride upto10-12\% as compared with rice. This is due to the presence of higher amount of molybdenum in sorghum than rice. High molybdenum intake leads to cause secondary deficiency of copper which is an essential element for bone development. Absorption of fluoride from food is more complicated and a variety of dietary factors can either increase or decrease the amount of fluoride content in the body. The availability of fluoride from various food materials was reported to vary from 2 to $75 \%$ in humans. Mineral level and $\mathrm{pH}$ of the food items are the important factors on the bioavailability of fluoride. Children and adults in high fluoride endemic areas are highly exposed to fluoride through drinking water, as much as 50 and 30 times more than the recommended level of 0.05 $\mathrm{ppm} / \mathrm{day}$.

\section{CONCLUSION}

This study identified few fluoride endemic villages in Dindigul district of Tamilnadu, where the drinking water fluoride level is higher than the recommended level of safety. Hence, it is recommended that the municipal and local Government authorities may take serious steps to supply drinking water with low fluoride to the identified fluoride endemic villages in various blocks of Dindigul district. More than 80\% of the humans in Vadamadurai block are found to be affected by fluorosis, but the other neighboring blocks are almost free from excess fluoride contamination in drinking water. High fluoride concentration present in drinking water in this block may be due to geological formation. Both adults and children are faced with higher risk of fluorosis in Vadamadurai block and infants from all the blocks consume high fluoride. The results may suggest the Government authorities to establish defluoridation plants in four severely affected villages. The statistical data indicate that the fluoride level in water is a primary pathway for the exposure of fluoride dosage. Based on the present findings, we suggest the local Government authorities to build defluoridation tanks, conduct awareness programmes in villages in schools by using audio-visual aids, pamphlets, news papers, TV, radio and other social media.

\section{REFERENCES}

1. G. Karthikeyan, A. Shanmugasundarraj, Isopleth mapping and In-Situ fluoride dependence on water quality in the Krishnagiri block of Tamil Nadu in south India. Fluoride, 2000, 33(3): 121-7 and the references cited therein.

2. G. Karthikeyan, P. Anitha, B.V. Apparao, Contribution of fluoride in water and food to the prevalence of fluorosis in areas of Tamil Nadu in South India. ISFR, Fluoride 1996, 29: 151-5.

3. N. Kundu, M. K. Panigrahi, S.P. Sharma, Environ. Geo, 2002, 43, 228-235.

4. A.K. Susheela, A treatise on fluorosis, Fluorosis Research and Rural Development Foundation1st ed.; 2000. p. 1-119. New Delhi, India. 
5. Q. Xiang, Y. Liang, L. Chen, C. Wang, B. Chen, X. Chen ,M. Zhou, P.R. Shanghai, Effect of fluoride in drinking water on children's intelligence. Fluoride, 2003, 36(2): 84-94.

6. M. Bishnoi, R. Malik, J. Environ. Bio, 2007, 29(6), 881-886.

7. S. Bhupinder, J. Environ. Res. Tech, 2011, 1, 45-50.

8. R. Srikanth, T,R, Chandra, B.R. Kumarb , Res. Repo. Fluor, 2008, 41(3), 206-211.

9. N. Kundu, M.K. Panigrahi, S. Tripathy, S. Munshi, M.A. Powell, B.R. Hart, Environ. Geol, 2001, 41(3-4), 451-460.

10. K. K. Das, T. Panigrahi, R. B. Panda, J. Environ, 2012, 1(2), 33-39.

11. J. Cao, Z. Yan, L. Jianwei, Fluoride in the environment and brick-tea-type fluorosis in Tibet. J. Fluor. Chem, 2000, 160: 93-97

12. A. Goyal, K. Gaupa, A. Tewari, Bioavailability of fluoride inhuman from commonly consumed diets in India. J. Ind. Soc. Pedod. Prev. Dent. Dis, 1998, 16: 1-6.

13. R.W. Kahama, D.N. Kariuki, H.N. Kariuki, L.W. Njenga, Fluorosis in children and sources of fluoride around Lake Elementaita region of Kenya. Fluoride, 1997, 30(1): 19-25.

14. D.L. Ozsvath, Fluoride and environmental health: A Review. Rev. Environ. Sci. Biotech, 2009, 8(1):59-79.

15. G. Viswanathan, S. Gopalakrishnan, S. Sivailango, Assessment of water contribution on total fluoride intake of various age groups of people in fluoride endemic and non-endemic areas of Dindigul District, Tamil Nadu, South India. Water Res, 2010, 44: 6186-6200 and the references cited therein.

\section{* Corresponding Author: Somasundaram N,}

Department of Chemistry, Rukmini Shanmugam Polytechnic College, Varichiyur, Madurai, India 